\title{
Does Double Reduction Policy Decrease Educational Pressures on Chinese Family?
}

\author{
Xuepeng Jin ${ }^{1, *}$, , Yirong $\operatorname{Sun}^{2, \dagger}$ \\ ${ }^{1}$ School of Foreign Languages, Tianjin Chengjian University, Tianjin, Tianjin, 300384, China \\ ${ }^{2}$ College of Communication, Boston University, Boston, Massachusetts, 02215, USA \\ *Corresponding author. Email: wendys21@bu.edu \\ Those authors contributed equally.
}

\begin{abstract}
Education is the core of a nation, which determines its future. Thus, education reforms play an indispensable role during the whole process. Recently, Chinese government put forward a new policy called "Double Reduction" aiming to relieve the study burden of Chinese families. This research paper focuses on its influence to Chinese families and answering the following question. Does the double reduction policy really relive parents' anxiety of children's academic performance? Through questionnaires and the analysis of data, most of parents become more anxious than before for the high-stake examination still exists but the cram schools are banned. Therefore, majority of parents choose to tutor their children by themselves or hire expensive one-on-one teachers. This paper shows some aspects of the influence of the policy and put forward some solutions that could be taken into consideration.
\end{abstract}

Keywords: Double reduction policy, Pressure, Examination, Equality.

\section{INTRODUCTION}

High-quality Education is a scarce resource of society. With the limited position of society and people's increasing awareness of education, education has become more important in many families, thereby resulting in abnormal competition in educational resources. In China, the government announced a double-reduction education policy in May 2021 and announced its implementation in September, saying it was intended to ease parents' anxiety and students' pressure. But the policy has become a heated debatable topic in society. Therefore, this study focuses on the impact of the double reduction policy on parents, with the form of a questionnaire to understand the views of parents on this policy and policy's implementation effect.

\section{LITERATURE REVIEW}

\subsection{The definition of Double Reduction Policy and its purposes.}

Double reduction policy includes two decreases [1]. The first one is a reduction in the total amount and time of commitment required by school homework, which means that students now have less homework than before they have. The another one is a reduction in the burden of off-campus or after-school training programs, which means that students now have fewer extra classes in their after-school lives.

The purpose for double reduction policy includes three aspects [2]. The first one is that people should adhere to the public welfare attributes of education. This purpose is to solve the problem of the current chaotic education and training industry. Since educational equity is the cornerstone of social equity, it cannot become a luxury and a rich people's patent. The second purpose is to correct the educational perspective. This purpose is to solve the problem of the anxiety of families that let their children learn ahead of time. And correction includes four points: correcting the bias of educating children, the illegal of competition, the problem of advanced learning, and the problem of overburdened. The last purpose is the explanation of basic provisions of education. This responds to optimization to meet the diverse needs of students. Students should develop comprehensive instead of developing specifically, education should insist both physical and psychological development in a harmonious way, and teachers should teach students in accordance of their aptitude. 


\subsection{Chinese educational dilemma before the reform}

Capital itself is inherently profit-seeking. When education which is a field with very prominent, encounters an "overheated" capital market, some more serious problems emerge. Before the "double reduction," off-campus training in the compulsory education stage was very "hot", and the education and training industry has developed a trillion-level market dominated by off-campus training institutions. The excessively hot and intense subject-based off-campus training has caused a particular impact and negative impact on the average pace of teaching in the school. As this small group of students has made faster and more complex "advanced learning" and "excessive questioning" by training institutions outside of class, they have gradually lost interest in the average pace of classroom teaching [3]. Their ability to concentrate in the classroom is reduced. As a result, students who are not in the institution's advancement and over study's average progress have been harmed, and the educational resources they should have received have been robbed.

In addition, before the double reduction reform, most students in the compulsory education stage had great academic anxiety (overburdened by students' homework and extra-school training), and contemporary parents had double anxiety about finances and energy (overburdened by finances and energy) [3]. Specifically, as far as parents are concerned, due to busy work, some parents have shifted their children's training tasks to the education market created by capital, and many parents do not know how to play the role of parents. Follow the crowd blindly, they have not seriously considered whether they are suitable for their children. There are some "tiger fathers/mothers" paid for their children into extracurricular tuition institutions [4].

More importantly, parents often experience "unnecessary" anxiety. After the arrival of the Internet era, there will be more information circulation, which also adds to parents' anxiety. This has been exacerbated by popular film and television dramas, self-media articles, "babies" on short video platforms, and information dissemination in parent groups. The K12 education market boosted by capital has played a role in fueling the flames, playing an essential role in creating such unnecessary consumer demand. Regarding this point, Marcuse Herbert mentioned the two concepts of "real" need and "false" need in modern society in his book "One-Dimensional Man." In Marcuse's view, those who "live and consume according to advertising" are "false" needs [3].

This "false" need only increases parents' unnecessary anxiety. It also increases the pressure on primary and secondary school students and has irreversible effects on their physical and mental health.
In March 2021, the "Chinese National Mental Health Development Report (2019-2020)" issued by the Institute of Psychology of the Chinese Academy of Sciences showed that the phenomenon of insufficient sleep among adolescents is becoming more and more serious. In 2020, the detection rate of depression among adolescents in China is 24.6\% [5]. In addition, longterm participation in online tutoring classes has also caused children's vision to plummet. The incidence of myopia in Chinese adolescents is gradually showing a trend of younger age. In 2018, the overall myopia rate of adolescents and children in my country was $53.6 \%$. The detection rate of poor vision among elementary school students was $36.0 \%$, that of junior high school students was $76 \%$, and that of high school students was $81.0 \%$ [5]. Young people's nearsightedness and younger age have become a problem that cannot ignore in the current society.

The differences in the financial strength of parents and the pressure of education have led to more differentiation in education equity [3]. Although education equity cannot be fully realized, we can only continue to move towards relative equity. However, extracurricular supplementary lessons for training classes have further increased the imbalance of education equity. Wealthy families can apply for various good training courses to supplement lessons for their children and improve their children's performance. However, families with ordinary economic conditions can only receive a school education [6]. Moreover, everyone reports for training courses, which will undoubtedly intensify competition, making internal scrolling more serious and education anxiety more serious.

A combination of many factors determines the inevitability and urgency of "double reduction." "Double minus" is the moment when it must be started.

\subsection{Eeducational reform in South Korea}

In South Korea, it is common that school finishes at $3: 30 \mathrm{pm}$ and students go to various extracurricular clubs for another 3 to 5 hours [7]. In China, a sea of students' weekend is also filled with subject-based training courses [8]. These are standard phenomenon for most students in Asia. Obviously, the education mania sweeps the whole Asia.

To prevent the unhealthy educational model, the Chinese government put forward "Double Reduction" policy. It is similar to the educational reform of South Korea on 30th July,1980. At that time, the school education in Korea was distorted, due to the fierce competition for the entrance examination of college as well as the overheated cram schools, which occupy the rest time of students. The main educational reforms of 1980 were as follow: First, increase the number of 
college entrance examinations and reduce the degree of competition. Second, teachers from schools are forbidden to pay for extracurricular tutoring activities and the violators are severely punished. Third, establish an education management committee to regulate the order of extracurricular tuition [9]. However, after a few years, the reform failed, because the high-stake examination still exists in children's early life. Cracking down on tutoring did not solve the most fundamental problem. It means that one child gains another child losses. Some parents who live in opulence still hire expensive teachers tutoring their children in their houses. Thus, other parents were unsatisfied with this unfair phenomenon. They acclaimed that the reforms deprived children's rights to accept education. Therefore, under the high-pressure of parents' calling, the government canceled the reform and restored the extracurricular clubs in the year of 2000 .

The education system is the real cause to fuel education mania in eastern Asia, which pits people against each other early in life and give extreme rewards for those who graduate from the prestigious universities.

\subsection{Hypothesis}

Due to the limitations of the timing of the implementation of "Double Reduction" policy, the above is only an analogy between the introduction of the policy and the impact of similar policies in Korea. Combined with the current situation of society and the original intention of the policy, parents are still anxious about the education of students. This study will analyze the factors that parents are anxious about the education of their students under the Double Reduction policy. Below are three research hypotheses:

Hypothesis 1: Under the reform of "Double Reduction", parents would continue to send their children to accept extra subject-based training courses or tutor their children by themselves for the entrance examination of high schools still exists.

Hypothesis 2: The double reduction policy will lead parents to become anxious about expanding their students' extracurricular courses and hobby development.

Hypothesis 3: The long-formed habit of off-campus training was suddenly restricted and cancelled under the double reduction policy, and parents could not immediately change their minds.

\section{RESEARCH METHODS}

This study will use quantitative research methods. This research requires that all participants have at least one child who is in elementary or junior high school. The purpose is to be able to measure the results of the research accurately. In this study, a total of 300 participants filled out an anonymous quantitative questionnaire. To facilitate the collection of questionnaires and allow participants to participate and familiarly, this online questionnaire is randomly distributed to the WeChat platform (a Chinese social application). The questionnaire has 20 questions, and the first includes some basic personal information, such as social and economic strength. Secondly, the questionnaire sets easy-to-answer and straightforward questions, such as multiple-choice questions (divided into single-choice and multiple-choice) and subjective questions (choose a number from 1 to 10 to indicate the degree). It takes about 5 minutes to complete the entire questionnaire. At the end of the questionnaire, it will state that the optional data of the questionnaire will be fully recorded for further transcription and data analysis and will not disclose to anyone other than the researcher.

\section{RESULTS AND DISCUSSIONS}

\subsection{Hypothesis 1}

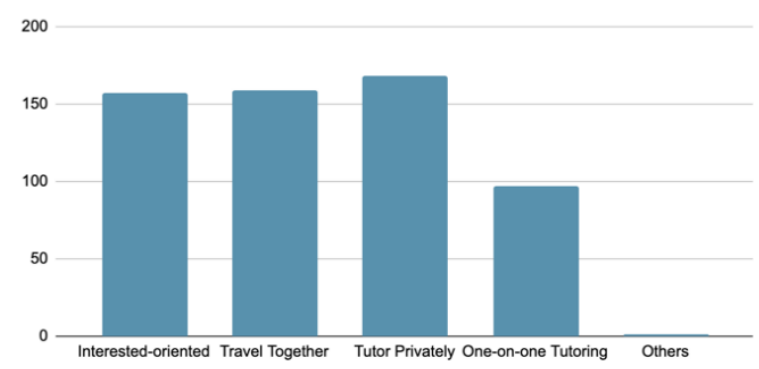

Figure 1 The Distribution of Parents' Arrangements for Children's Extracurricular Activities under the Policy

Hypothesis 1 is: Under the reform of "Double Reduction", parents would continue to send their children to accept extra subject-based training courses or tutor their children by themselves for the entrance examination of high schools still exists. Figure1 illustrates that after the implement of "Double Reduction" policy, more than $50 \%$ parents would tutor their children privately outside school and $32.01 \%$ parents would continue to find private teachers to teach children. On the other hand, $51.82 \%$ of parents prepare to engage their children in interested-oriented learning courses. Based on the research, over half parents need to follow their children to study and help them to understand deeply. Also, though the costs of private teachers are high, there are still over one thirds parents choose this way to improve children's academic performance. Nonetheless, not all the figures support hypothesis 1. Figure 1 also represents that $52.48 \%$ of parents would accompany their children to have a travel in spare time. 
Figure2: How many extra-courses would parents to choose for their children?

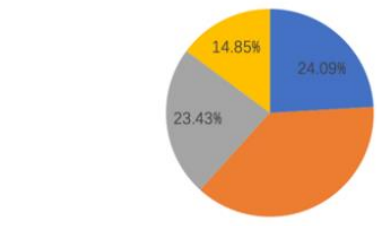

- one subject a two or three subiects nover three subjects nnone

Figure 2 The Distribution of the Number of Children's Extra-courses

According to Figure2, the pie chart shows that how many extra subjects would parents add to their children. From the data, nearly $40 \%$ parents would choose 2 or 3 subject-based courses as supply and $23.43 \%$ parents even prepare to engage their children in over 3 subjects. On the contrary, there are only $14.85 \%$ parents choose not to find tutors to help children's study. It is obvious that the policy does not solve the rooted issues for so many parents still try to add extra courses to their children.

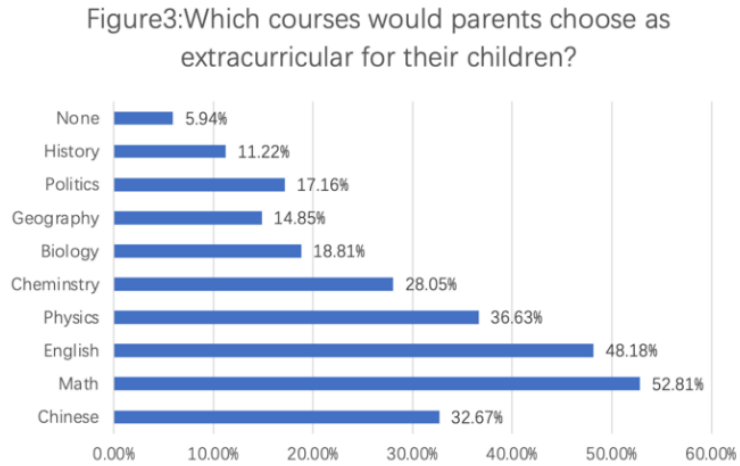

Figure 3 The Distribution of Types of Extracurricular Tutoring Subjects for Children

Figure 3 demonstrates that $52.81 \%$ of participants would add math courses to children followed English courses which accounted for $48.18 \%$ of the participants. Subsequently, $36.63 \%$ of the parents would choose physics. Based on the data, parents still lay much emphasis on the science study of students. Because, in our modern society, an increasing number of IT industries emerge, which provide more opportunities and higher wages.

\subsection{Hypothesis 2}

The Hypothesis 2 is The double reduction policy will lead parents to become anxious about expanding their students' extracurricular courses and hobby development. Since the double-reduction policy does not interfere with students' extracurricular interest courses, interest courses have become an option for many parents to schedule their children's after-school hours. At the entry threshold in many schools, students with additional skills or expertise are better off than children of the same level. Therefore, the double reduction policy will cause parents worries about their children's academic work, from in-class learning to extracurricular learning.

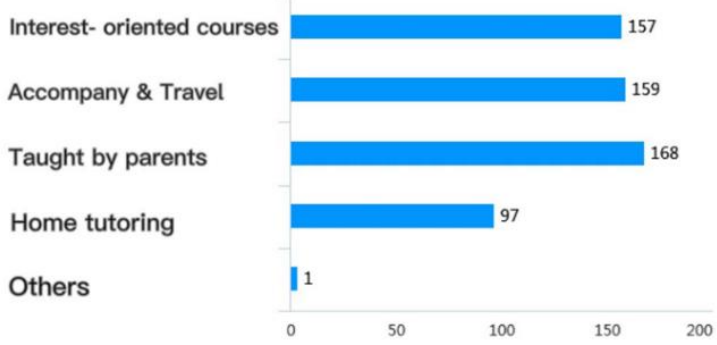

Figure 4 The Distribution of Children's After-school Living Arrangements after the Implementation of the Policy

Figure 4 illustrates the time arrangement of children after school life by their parents. About $52 \%$ of parents choose to fill their children's weekends by enrolling them in extracurricular courses. According to this, more than half parents intend to make their children versatile and become competitive. In addition, parents' attitude levels towards extracurricular activities are seen to be at a very good level in all dimensions, and due to schoolage children experience emotions after sitting for long periods of time, they need extracurricular activities and interest development [10]. In addition, in research that focused on children's engagement in extracurricular activities from the perspective of middle-class parents, they think extracurricular activities are as important for children's success and activities as preparing children for adult life, emphasizing competition and accomplishment [10].

\subsection{Hypothesis 3}

The Hypothesis 3 is: the long-formed habit of offcampus training was suddenly restricted and cancelled under the double reduction policy, and parents could not immediately change their minds.

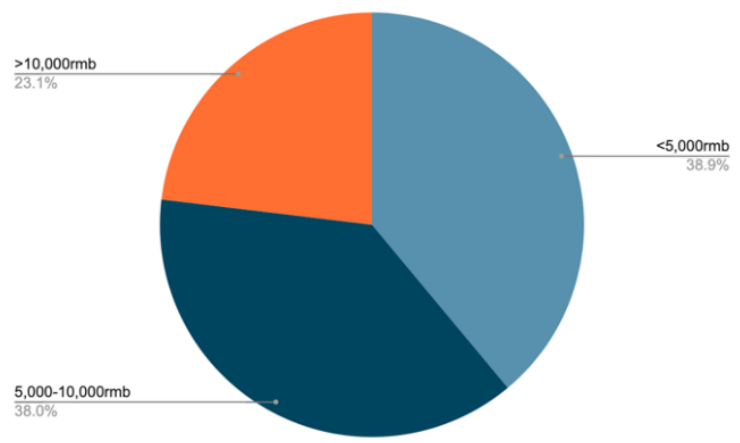

Figure 5 The Distribution of Monthly Extra Tuition Expenditures for Children by Parents before the Policy 


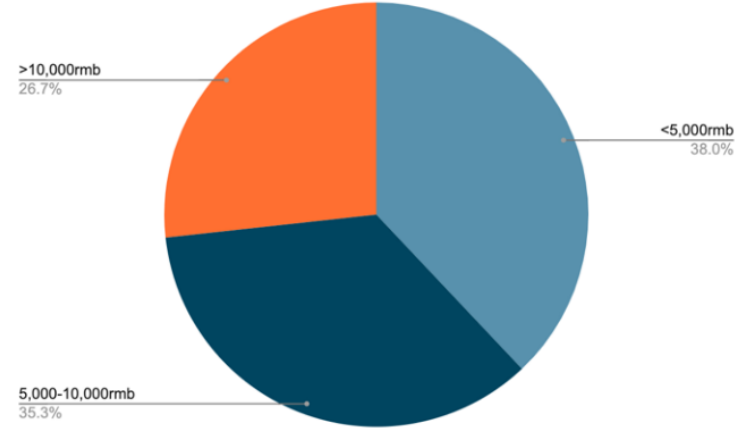

Figure 6 The Distribution of Monthly Extra Tuition Expenditures for Children by Parents after the Policy

In Figure 5, before the implementation of the double reduction policy, in the questionnaire data of the supplementary tuition fees that parents invested in their children, $38.9 \%$ chose less than 5,000 RMB, 38.0\% chose the middle of 5,000-10,000 RMB, and $23.1 \%$ chose 10,000 or more. In Figure 6, after implementing the double reduction policy, there is no significant difference in the data on the supplementary tuition fees that parents invested in their children. $38.0 \%$ chose below 5,000 RMB, 35.3\% chose the middle of 5,000$10,000 \mathrm{RMB}$, and $26.7 \%$ chose 10,000 RMB. above. These data show that the double reduction policy has not essentially alleviated the educational pressure of parents.

The training habit formed for a long time outside school was suddenly restricted and cancelled, and parents of students could not immediately change their minds. Although extracurricular tutoring is prohibited under the double reduction policy, the pressure on parents' education is still there. From the data, after the double reduction policy, the number of people who spend more than 10,000 RMB has increased, which shows that some parents have chosen to ask one-on-one to help their children learn. Specifically, although the double reduction policy has been implemented, the difference in the quality of education under the private and public, the existence of examinations for entrance examinations and other factors, have caused the double reduction policy not to relieve parents' educational pressure in a short time. Thus, the masses are still holding a wait-and-see attitude towards the "double reduction" policy.

\section{CONCLUSION}

This research paper focuses on three aspects for the influence of the reform of "Double Reduction" in China: What parents plan to do after the implement of the policy? Does parents' burden of the costs of crams schools really be alleviated? Are parents relaxed than they were before the implement of the policy?

Based on the refection on quantitative questionnaires, there are some findings being discovered. 1) Some parents have become more anxious than before since the academic scores of their children are not disclosed. They cannot keep track of their children's learning situation in time. They also concern that their children will lag behind their peers and be eliminated in the final test; 2) The majority of parents will continue to find private teachers to instruct their children because the examination of high schools still exists. Parents all wish their children to enter a good high school afterward entering an elite university. They all expect that their kids would have a better life and find a decent job after graduation; 3) The fierce competition is still among students and parents. This survey reflects the public perspective on the reform of "Double Reduction" in China.

Education is the core of a nation, which represent its nation. Meanwhile, parents all wish to have brilliant offspring. What's more, education mania in east Asia is truly fueled by the systems that pit individual against each other early in life. The rooted conscientiousness of people is that there is only one way to achieve the ascend of social class, that is, study and surpass your competitors. This paper aims at spreading the public's attitudes as well as parents' action toward the new reform. Some potential solutions can be concluded or derived from the questionnaires. The better way to alleviate the overheated cram schools and the fierce competition among students is to remove the high stakes exams early in life rater that cracking down on tutoring. In addition, schools and educational institutions can put forward some classes that lead students to find their interests. What's more, investing more in trade schools is another rewarding choice; and it is suggested to encourage universities to select students not just through examination but students' comprehensive ability.

\section{REFERENCES}

[1] The implementation of the "double reduction" policy allows education to return to its essence. (2021). The Beijing Government. Retrieved October 16, 2021, from http://kfqgw.beijing.gov.cn/zwgk/xwzx/yzxw/2021 07/t20210730_2451855.html

[2] Zhang, Z.Y. (2021). After the implementation of "Double Reduction" policy, the perspective toward education changed. Wenzhou Education Bureau. http://edu.wenzhou.gov.cn/art/2021/8/11/art_13245 55_59018812.html

[3] Wang, Z.J. (2021). Why do we have to "double subtract". Xinminweekly. https://m.xinminweekly.com.cn/content/16449.htm 1

[4] Chen, Y.L. (2021). Chinese "tiger mothers" have a new favourite - the traditional cram school has 
long been outdated. Sohu. https://m.sohu.com/n/478071690/?wscrid=95360_9

[5] The 2020 edition of the "Blue Book of Mental Health" is released: $24.6 \%$ of teenagers are depressed and lack of sleep is getting worse. (2021). Sohu. Retrieved October 16, 2021, from https://www.sohu.com/a/454896284_116237

[6] He, L.Q. (2021). Oral by parents in 7 cities / Under the "double reduction" policy, how to resolve the remaining anxiety and pressure. Thepaper.

https://www.thepaper.cn/newsDetail_forward_141 00573_1

[7] Robin, H. (2021). Halting East Asia's Education Arms Race Could Help Birth Rates. Financial Times. https://www.ft.com/content/d38a9fea-d58742d6-b62d-089087011796/

[8] The current situation of Chinese education: Parents have no freedom, Children have no childhood. (2021). Tencent News. Retrieved October 16, 2021, from http://xw.qq.com/cmsid/20210425A08KCR00?f=n ewdc

[9] History of Education in South Korea. (n.d.). K12academics. Retrieved October 16, 2021, from https://www.k12academics.com/Education $\% 20$ Wo rldwide/Education\%20in\%20South\%20Korea/histo ry-education-south-korea

[10] Parenting in America. (2015). Pew Research Center. Retrieved October 16, 2021, from https://www.pewresearch.org/socialtrends/2015/12/17/5-childrens-extracurricularactivities 